\title{
A Modest Suggestion: Baking Using Sourdough - a Sustainable, Slow-Paced, Traditional and Beneficial Remedy against Stress during the Covid-19 Lockdown
}

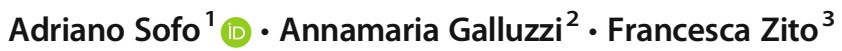 \\ Accepted: 3 February 2021 / Published online: 12 February 2021 \\ (C) The Author(s), under exclusive licence to Springer Science+Business Media, LLC part of Springer Nature 2021
}

\section{Introduction}

The rise in Covid-19 infections and the consequent social isolation have led to a widespread surge in interest in home baking, particularly of sourdough breads. In Italy, one of the countries hardest hit by Covid-19, and in many other countries, social gatherings beyond household members are discouraged. People are advised to limit their shopping excursions to essentials, and some processed products that use flour are increasingly hard to find and expensive, so many families, temporarily or long-term unemployed cannot easily find or afford them.

As healthcare workers, grocery-store clerks, couriers, and others whose labor has been deemed essential to continue to put their own lives at risk, being stuck at home is in many respects a privilege. Living with home restrictions certainly helps save lives and limit the spread of the virus, but on the other hand can be extremely stressful, often leading to feelings of claustrophobia, loneliness, depression, frustration, boredom, anxiety, and insomnia (Goldman 2020; Rossi et al. 2020). Furthermore, readily available lengthy stretches of free time can appear somewhat dispiriting (Cellini et al. 2020). Therefore, it is necessary to find strategies to preserve physical and mental well-being while avoiding negative psychological effects during the Covid-19 lockdown (Hiremath et al. 2020).

The pandemic has deprived us of much of our in-person social life but has also been a reminder that domestic labor such as cooking and baking can provide both pleasure and

Adriano Sofo

adriano.sofo@unibas.it

1 Department of European and Mediterranean Cultures: Architecture, Environment and Cultural Heritage (DiCEM), University of Basilicata, Via Lanera, 20, 75100 Matera, Italy

2 Trani, Italy

3 Matera, Italy pride while fulfilling basic family needs. In this difficult and unprecedented period, when these needs have assumed increased importance, it is no surprise that many people have started to dedicate their efforts and time to produce sourdough for baking, a natural and non-commercial yeast (Lidz 2020; Sponagle 2020). Sourdough has been developed through trial and error and used for millennia around the globe as a major starter for bread-making (Papadimitriou et al. 2019). With the shortage of yeast in many supermarkets because of the pandemic, sourdough has recently become popular.

Here we focus on the benefits of sourdough as food, as contributing to psychological health, and as an economic strategy in this period of forced isolation. For many of us having to adapt to household isolation, which negatively affects our brain activity (Goldman 2020; Rossi et al. 2020), we need a focus to keep our bodies and minds active, something to provide satisfaction and gratification that can also be fun, a pastime that all family members can participate in (Hiremath et al. 2020).

In this lockdown period dominated by digital media (Cellini et al. 2020), many city dwellers in particular are unable to experience the pleasures of natural environments such as woodlands and grasslands (Lambert et al. 2015). Setting up a sourdough culture to sustain, refresh and use could seem, at a first glance, a somewhat inadequate response to these hard and uncertain times. But a living culture can, in some respects, mimic having a pet. Also, since food is closely associated with psychological, cultural, and social determinants, we here describe the positive aspects of cultivating sourdough, illustrating with practical examples, recipes, and experiences. We hope this will allow us to remember the multifunctional nature of food, particularly relevant in this complicated period.

\section{Some Brief Preliminaries on Yeasts}

Yeasts are microscopic fungi belonging to the Ascomycetes group. They have not the mycelium, the body typical of mushrooms, but consist of single-celled fungi living in colonies and usually reproducing by budding or, more rarely, by spores. 
Under the microscope, they appear spherical, oval, or filamentous. Some yeasts use oxygen, just like higher organisms (aerobic respiration). Others in cases where oxygen is scarce or even absent can switch to anaerobic respiration, also called fermentation. The yeast cells contain the enzyme zymase, which allows the degradation of the sugars of the substrate (i.e., the food on which the yeast is deposited, for example, flour, grape must, malt, etc.) into molecules smaller than glucose. The energy of the chemical bonds thus released allows the yeasts to live.

The word 'yeast' has a Germanic origin (Dutch 'gist' and German 'Gischt' - 'froth, yeast') from an Indo-European root shared by Greek 'zein,' to boil. The Italian word for yeasts is 'lievito,' which derives from the Latin 'levis,' light. Indeed, leavened baked products are airy and light because of their low density. The traditional baking consists of mixing water, flour, a little yeast, and covering the mixture with a damp cloth. Shortly thereafter, the dough begins to swell, and it is ready for cooking.

The most popular type of yeast, available in supermarkets, is the industrially-produced and human-modified brewer's yeast, fresh in the form of loaves. It is used in the preparation of bread and many other sweet or salty baked goods, but also for wine and beer production. A commercial alternative to brewer's yeast is dry active yeast, usually used in bread making. Sourdough, also called acid yeast or natural yeast, is on the other hand obtained from a mixture of flour and water that absorbs yeast strains that are free in the air or present in the flour. After a few days, if the conditions are favorable, colonies of wild yeasts will form in association with lactic acid bacteria (LAB) (Gobbetti et al. 1994; Corsetti and Settanni 2007). Sourdough tends to give bread a more acidic flavor. Special conditions are required to activate the yeasts and allow fermentation. For example, in the case of bread, the leavening process has an optimal temperature of around $20-25^{\circ} \mathrm{C}$ and requires a humid and sheltered environment. This temperature range is fundamental to prevent yeast cells from being less metabolically-active or dying. Both industrial or natural yeasts ferment by transforming glucose into ethyl alcohol and carbon dioxide (alcoholic fermentation). Carbon dioxide is retained by gluten and makes the dough swell, while most of the ethyl alcohol evaporates (Logan and Distefano 1998). Baking blocks the chemical process of yeasts and, starting from 100 to $150{ }^{\circ} \mathrm{C}$, the crust forms on the surface of the dough, which then caramelizes, becoming yellow-brown.

Yeasts are not only present in the air but also on the skins of fruit. Saccharomyces cerevisiae and Saccharomyces ellipsoideus (also called wine saccharomycetes) are abundant in the wax peel of grapes and when it comes into contact with the must (the juice obtained from the pressing of the grapes), they trigger alcoholic fermentation. This kind of fermentation is identical to that of bread making. However, in the case of grapes, carbon dioxide is dispersed in the air during a phase called 'tumultuous fermentation,' while ethyl alcohol remains in solution giving the wine its alcoholic strength. To make beer, barley is fermented together with rice or wheat. The barley starch soaked in water macerates for about ten days, turning into maltose and then into glucose (together they form the 'malt'). 'Lupulin,' a powder obtained from the dried flowers of the hops, is added to the malt to give the beer its typical bitter taste, and the saccaromycetes activate the alcoholic fermentation.

\section{Sourdough Basics and Preparation}

Despite consuming bread and leavened products daily, many people do not know exactly what sourdough is. Sourdough is obtained from the fermentation of a dough composed of water and flour, sometimes with the addition of sugary substances. From a microbiological point of view, sourdough contains a mixture of flour and water that is fermented by yeasts (more than 20 species of the genera Saccharomyces and Candida) and lactic acid bacteria (LAB; more than 50 species of the genus Lactobacillus) feeding on simple sugars (for example sucrose) or complex sugars (such as starch) (De Vuyst and Neysens 2005; Gobbetti et al. 2005; Corsetti and Settanni 2007). The yeasts that develop in the dough form a stable association that originates from natural contaminants in the air or the flour, or from a starter culture, but they are also determined by operational and environmental factors (Gobbetti et al. 1994; De Vuyst and Neysens 2005; Lebedenko et al. 2019). During their fermentation, all sourdough microorganisms produce specific 'waste' substances (e.g., carbon dioxide, lactic acid, acetic acid, and ethanol) that are indispensable to baking and give the final products a very distinctive aroma (Hansen and Schieberle 2005).

Fermentation and heat are two indispensable parameters for leavening to take place (Hammes and Gänzle 1998). For this purpose, dry or fresh forms of sourdough can be used. Compared to sourdough, brewer's yeast allows for quicker leavening, is always ready for use, and is easy to use, as well as making it possible to obtain leavened dough in shorter times and with 'weaker' flours, although this has a shorter shelf life as it ages faster.

The longer shelf life of bread made with sourdough is a consequence of the greater acidity of the dough during processing, which slows down the development of molds (Hansen and Schieberle 2005; Arendt et al. 2007; Catzeddu 2019). The formation of carbon dioxide, slower and more gradual than that produced by brewer's yeast, allows for the formation of a bread characterized by an irregular, sometimes open structure. The use of sourdough also guarantees an unmistakable aroma to bread, which tends to be accentuated during cooking thanks to the production of amino acids and sugars with volatile aromas (Arendt et al. 2007). Finally, bread prepared with sourdough is certainly more digestible than bread made with brewer's yeast 
thanks to the longer action of the enzymes during fermentation, capable of breaking down complex molecules into simpler substances (Catzeddu 2019). It is possible to get some of the benefits of sourdough through a 'pre-ferment' of a very small amount of baking yeast that is mixed with water and flour and allowed to ferment for approximately $12 \mathrm{~h}$ (more or less depending on the amount of yeast and ambient temperature). Pizza, focaccia, ciabatta, and other breads are commonly produced with preferments (Gobbetti et al. 2005).

There are many recipes and techniques to prepare sourdough that vary according to ethnic, social, commercial, and economic preferences (Lebedenko et al. 2019), but we present here a simple, empirical, and non-standardized method based on our personal experience. The basic ingredients for making sourdough are basically two: flour and water. To speed up the fermentation process, a substance called 'starter' can be added to provide nourishment to the microorganisms present in the flour.

The starters that can be used are:

- Grape must

- Juice or fruit pulp

- Honey

- Tomato

- Yogurt

- Barley malt

- Rye flour

The type of starter chosen will determine the degree of acidity you achieve.

\section{Experimental Setup}

Necessary tools and ingredients (Fig. 1a):
a) $100 \mathrm{~g}$ of "0" flour
b) $60 \mathrm{~g}$ of tap water
c) 1 spoon of honey as a starter
d) a kitchen towel (or plastic film)
e) a glass bowl
f) a kitchen scale and a graduated cup

Mix the water, flour and honey in the bowl, first with a spoon and then with your hands, until you have an elastic and homogeneous mixture. Make a cross incision on the dough to allow aeration and expansion (Fig. 1b). Moisten the tea towel and cover the bowl, then put it aside to rest overnight at a temperature around $25{ }^{\circ} \mathrm{C}$ (for instance in an oven switched off with the light on) (Fig. 1c).

Until midday of the following day, take care to keep the cloth constantly moist (or to avoid this, use transparent plastic film to cover the bowl). Check the dough, which should have slightly swelled, and remove the hard crust formed around it (Fig. 1d).

Next, take $100 \mathrm{~g}$ of the dough and add another $100 \mathrm{~g}$ of flour and $50 \mathrm{~g}$ of water. Carefully mix everything, cross-cut the dough, and let it rest as described above (Fig. 1e). This is the first refreshment phase of the dough.

On the morning of the third day, the dough should have more than doubled (Fig. 1f). When you remove the cloth (or
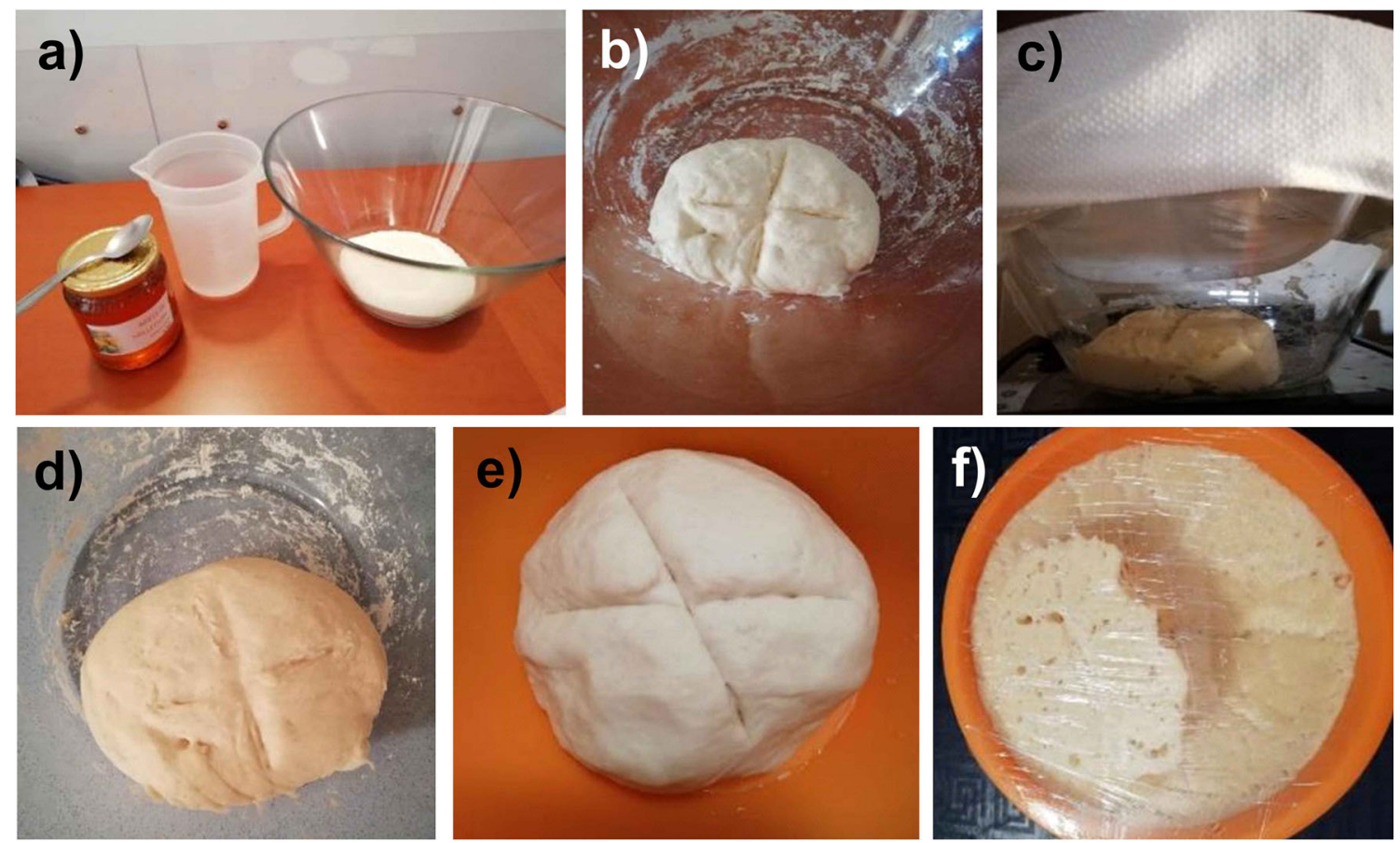

Fig. 1 Phases of sourdough preparation as explained in the text (photos: F. Zito) 
Fig. 2 Phases of the preparation of hand-made sourdough bread (photos: A. Sofo)
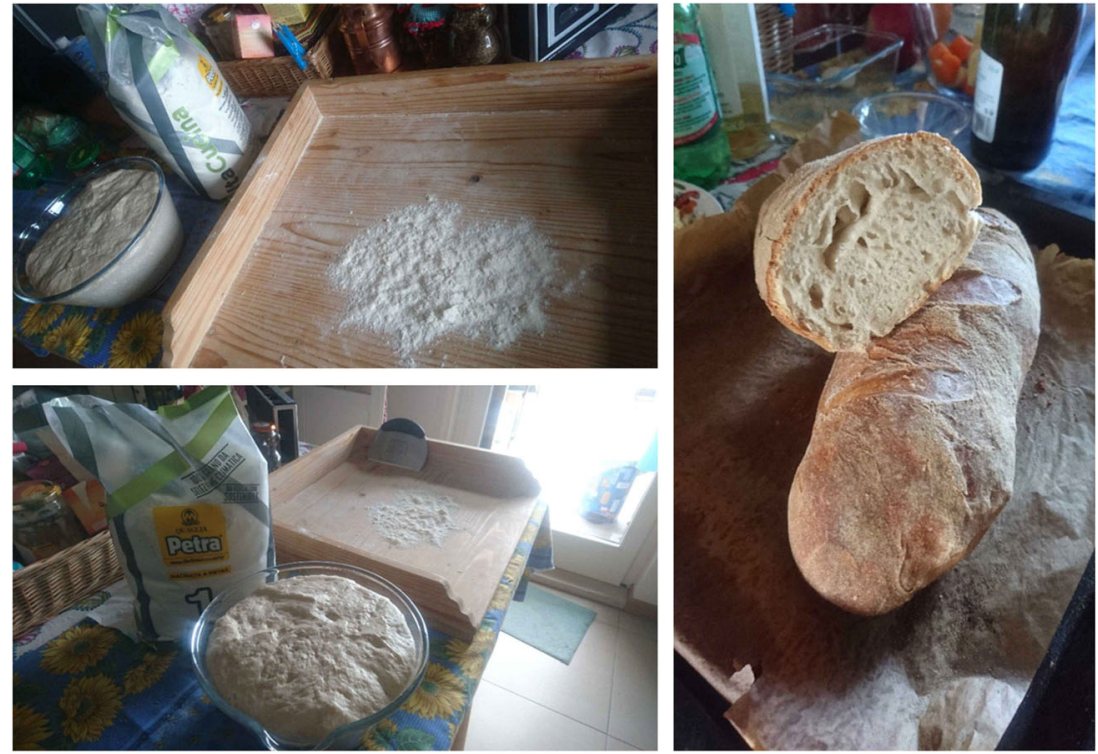

plastic film) you will recognize the classic sour and pungent smell of the sourdough, and the dough should be very soft, spongy, and honeycombed.

You then proceed to the third refreshment, always with the same proportions (2:1 w/w, flour:water) and period of rest. Do not put it in the refrigerator, as sourdough yeasts could die. If this happens, you will recognize it from the changed smell of the dough and from its liquid and mushy consistency.
Continue to refresh the dough $(2: 1 \mathrm{w} / \mathrm{w}$, flour:water) for at least the other two days up to a maximum of 10 days. At that point, the sourdough is ready to be used as a leavening agent.

\section{The Advantages of Sourdough as a Food}

With the move of consumer preferences away from mass produced packaged white bread, there has been an increased
Fig. 3 Savory dishes prepared with sourdough: a pizza, b focaccia, $\mathbf{c}$ taralli, and $\mathbf{d}$ fried zucchini (photos: A. Sofo)
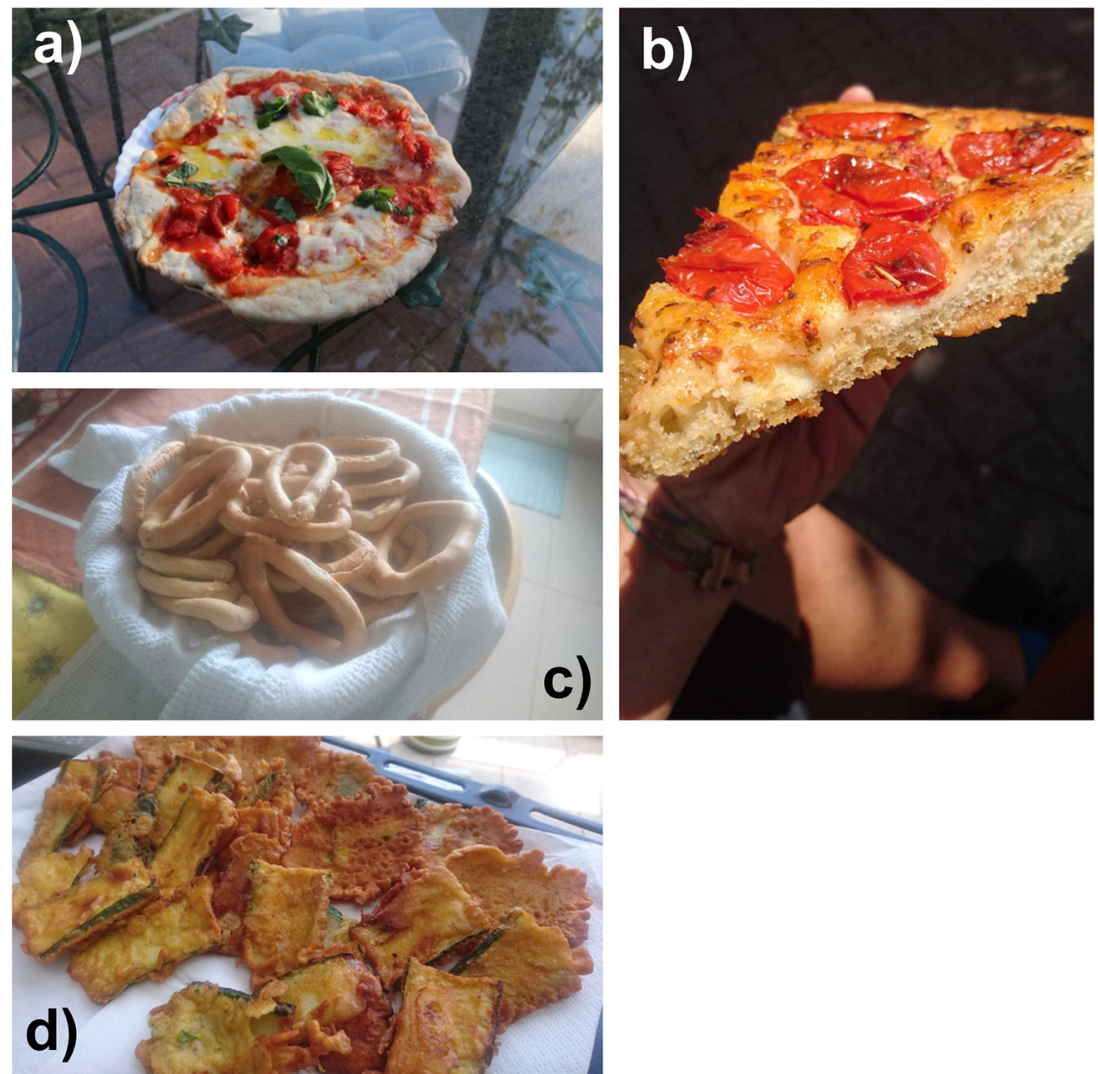
demand for tastier breads and a number of companies as well as smaller independent bakeries started to specialize in the production of stabilised sourdough products (Decock and Cappelle 2005). Sourdough can improve the quality, texture, elasticity, palatability, and aroma of bread (Hansen and Hansen 1996; Hansen and Schieberle 2005; Arendt et al. 2007). The antimicrobial substances (such as bacteriocins, antibiotics, and some organic acids) produced by its LAB increase bread stability and shelf-life (Gobbetti et al. 2005). Overall, many positive effects of sourdough on the technological, nutritional, as well as functional properties of bread have been described by many authors (e.g., Katina et al. 2005; Brandt 2007). Finally, people with celiac disease can tolerate sourdough-produced bread much more easily than bread made of the same ingredients but fermented with another type of yeast (Gobbetti et al. 2005).

In sourdough, the acid production adjusts $\mathrm{pH}$ to a range that favors the action of digestive enzymes, retarding starch digestibility. This leads to low glycemic responses, modulated levels, and bioaccessibility of bioactive compounds, and improved mineral bioavailability (Catzeddu 2019; Lebedenko et al. 2019). The diversity of sourdough microflora allows the production of a wide range of bioactive compounds, such as prebiotic oligosaccharides, vitamins, and sterols, many of them potentially protective compounds in blood circulation (Katina et al. 2005; Poutanen et al. 2009). Moreover, the enzyme phytase [myoinositol hexakis (dihydrogenphosphate) phosphohydrolase, EC 3.1.3.8] contained in sourdough can reduce or eliminate the antinutritional effect of phytic acid (Gobbetti et al. 2005).

We illustrate here some practical examples of the use of sourdough for preparing bread (Fig. 2), but also other dishes, such as classic pizza 'Margherita' (Fig. 3a), traditional focaccia (thicker than pizza but without mozzarella cheese and with olives; Fig. 3b), taralli (a traditional snack prepared with olive oil; Fig. 3c), fried zucchini (covered in batter; Fig. 3d), or sweet croissants (Fig. 4a-b), and brioches (Fig. 4c).

\section{The Multifunctional Role of Sourdough}

The production and consumption of sourdough can be traced back to several millennia $\mathrm{BC}$, as assessed from pottery remains from ancient Egyptian tombs, up to 8000 years ago (Papadimitriou et al. 2019). Today, we think of sourdough as a special type of bread but before the advent of commercial yeast sourdough was the only way bread was made (Harris 2003). The manner of sourdough use has remained virtually unchanged from antiquity until the late seventeenth century. The manufacture and consumption of bread has always been intimately linked to human subsistence and to traditional practices of civil society and religion. The languages throughout the world still retain expressions that reflect the close bond between life and bread (Cappelle et al. 2013).

Currently, changes in consumer eating patterns have modified the perception of bread from a basic food toward nutritious and
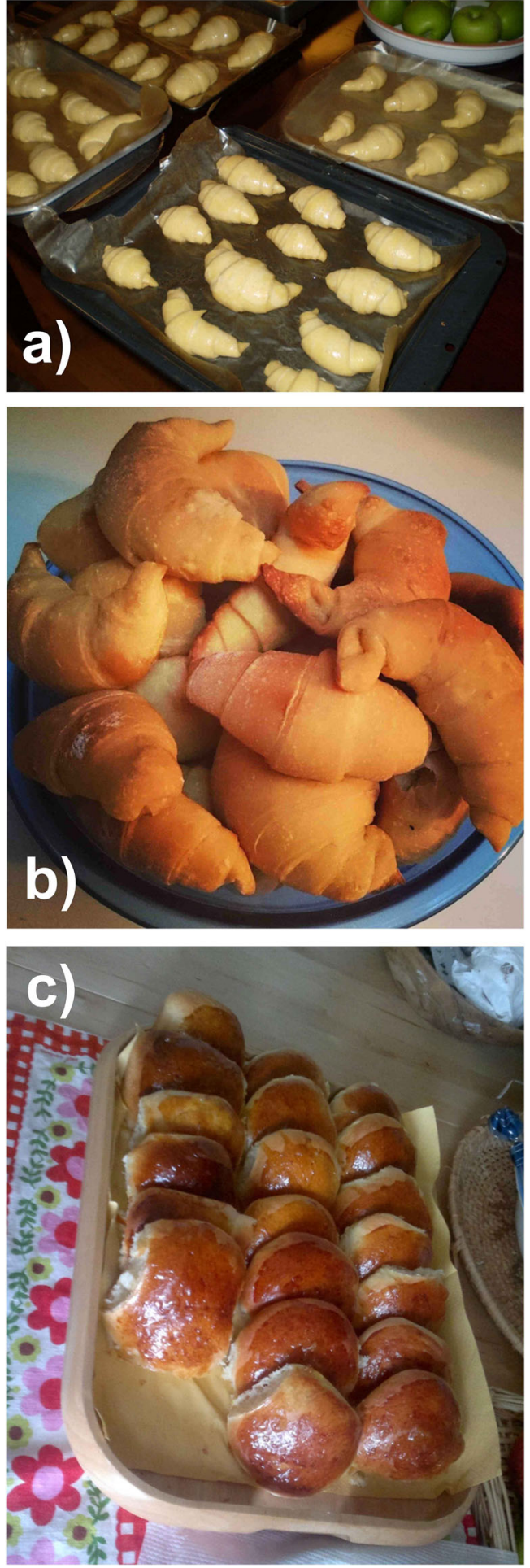

Fig. 4 Sweet dishes prepared with sourdough: a-b croissants, and b brioches (photos: A. Sofo)

healthy food, and, finally, to a symbol of cultural and traditional heritage. Thus, home baking of sourdough bread has come to be regarded as one aspect of increasing environmental awareness (Rosell 2019). Moreover, sourdough is perceived as a local product, since microorganisms particular to a given region enter the 
dough during fermentation, so each type of sourdough is composed of a different microbial association.

We might also regard this pandemic as an opportunity to rethink the capitalistic and globalized system on which our life is based. Maybe sourdough can help now but also be a practical example of how our world can be transformed into a sustainable system. Indeed, sourdough is at the cornerstone of a sustainable way of preparing food, aimed at selfproduction and social cooperation. It could indicate a new way of living that starts from daily activities, with a smallscale and bottom-up approach, based on sustainable use of

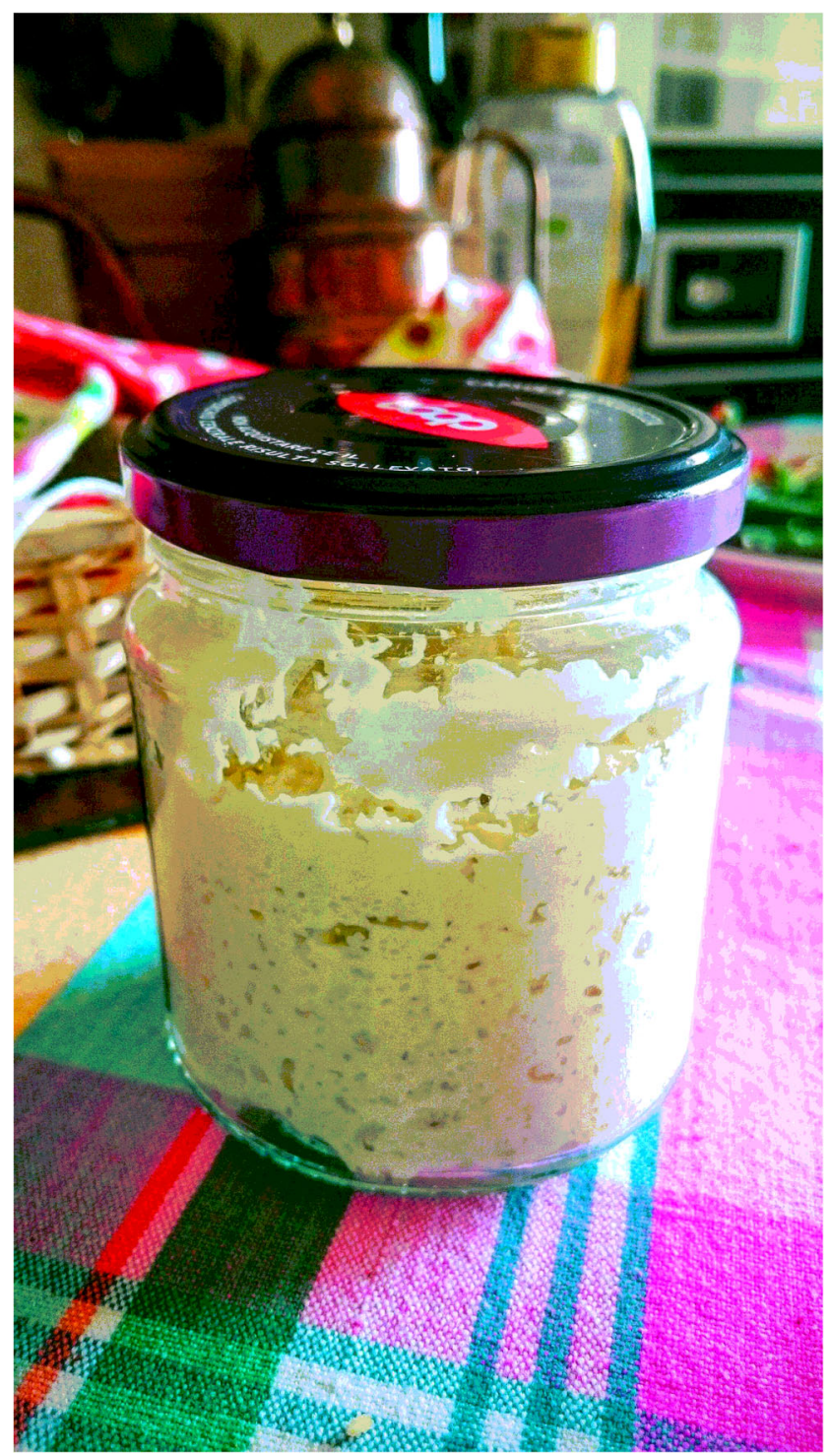

Fig. 5 Picture and text of a Facebook post by one of the authors: "I was created in California, where I contributed to the sustenance of my Creator with pizzas, wraps, pastries, croissants, bread, and turnovers. I died there four months later due to accidental causes. Earlier, however, a part of me had been given to another human being who, after a long journey through the Veneto, brought me back to my Creator, who was very surprised to find myself still alive. Now, I live in Trani, Italy." (photo: A. Sofo) food and promotion of a subsistence economy. This seems to be the function that sourdough has had in the recent past (Harris 2003). Although refreshing a sourdough may seem wasteful because it requires disposing of most of the yeast, on the other hand this can be a social advantage. Indeed, in many cultures the interpersonal exchange (horizontal) and intergenerational exchange (vertical) of sourdough is common practice, and this kind of barter strengthens social bonds in communities (Cappelle et al. 2013).

Homegrown sourdough can also generate an emotional bond resembling the way people relate to their pets. Indeed, with the massive use of digital media during the Covid-19 lockdown (Cellini et al. 2020), it is common to find posts and photos of sourdough experiences on the Web. Many people are making bread at home is a popular choice for passing the time, as illustrated by numerous photos of culinary tests shared on social networks (Sponagle 2020) (see also Fig. 5). As well as being providing food for the family, the positive feeling generated by putting your hands in the dough and kneading it can be a powerful antidepressant. It is indeed widely recognized that manual and creative activity, such as baking, have evident benefits for health and wellbeing.The multifaceted importance of sourdough has been recently celebrated by Karl De Smedt, the director of the Puratos Center for Bread Flavor, the world's most extensive collection of sourdough starters, located in St. Vith, Belgium, with the aim of preserving sourdoughs collected worldwide (Lidz 2020).

\section{Conclusions}

Alongside the inherent scientific interest, we argue that working with sourdough can provide considerable personal satisfaction. Making bread, pizza, or focaccia by yourself from simple ingredients can bring real joy and gratification. For many of us, it can be a source of amazement to understand that sourdough is not inanimate, but surrounds us, alive and with a remarkable ability to grow and regenerate quickly. The many uses of sourdough could also be incorporated into activities with children, to entertain them and stimulate their natural curiosity.

Nobody knows how the pandemic may continue impact our lives in the future. Certainly, the trends for the coming years could be to expand the use of sourdough as representing "a unique traditional product to get an otherwise un-reproducible quality of baked goods" (Gobbetti et al. 2005). In a world where everything has been turned upside down, sourdough represents a sustainable, slow-paced, traditional, and beneficial remedy to ease the mental and physical stress of living in lockdown.

Acknowledgements A. Sofo would like to thank Banafsheh Sadeghi (UC-Davis, CA, USA) and Marilu C. Carter (Carter International House, Davis, CA, USA) for their support and hospitality. 


\section{Declarations}

Conflict of Interest The authors declare they have no conflict of interest.

\section{References}

Arendt, E.K., Ryan, L.A.M., Dal Bello, F. (2007). Impact of sourdough on the texture of bread. Food Microbiology 24(2): 165-174. https:// doi.org/10.1016/j.fm.2006.07.011.

Brandt, M.J. (2007). Sourdough products for convenient use in baking. Food Microbiology 24(2): 161-64. https://doi.org/10.1016/j.fm. 2006.07.010.

Cappelle, S., Guylaine, L., Gänzle, M., Gobbetti, M. (2013). History and social aspects of sourdough. In: Gobbetti, M., Gänzle, M. (eds.) Handbook on Sourdough Biotechnology. Springer, Boston, MA, USA. Pp. 1-10. https://doi.org/10.1007/978-1-4614-5425-0 1.

Catzeddu, P. (2019). "Chapter 14: Sourdough Bread." In: Preedy, V.R., Ross Watson, R (eds.) Flour and Breads and their Fortification in Health and Disease Prevention (Second Edition). Academic Press, Cambridge, MA USA. Pp. 177-188. https://doi.org/10.1016/b9780-12-814639-2.00014-9.

Cellini, N., Canale, N., Mioni, G, Costa, S. (2020). Changes in sleep pattern, sense of time and digital media use during COVID-19 lockdown in Italy. Journal of Sleep Research 29(4): e13074. https://doi. org/10.1111/jsr.13074.

Corsetti, A., Settanni, L. (2007). Lactobacilli in sourdough fermentation. Food Research International 40(5): 539-558. https://doi.org/10. 1016/j.foodres.2006.11.001.

De Vuyst, L, Neysens, P. (2005). The sourdough microflora: biodiversity and metabolic interactions. Trends in Food Science and Technology 16(1-3): 43-56. https://doi.org/10.1016/j.tifs.2004.02.012.

Decock, P, Cappelle, S. (2005) Bread technology and sourdough technology. Trends in Food Science and Technology 16(1-3): 113-120. https://doi.org/10.1016/j.tifs.2004.04.012.

Gobbetti, M., Corsetti, A. Rossi, J. (1994). The sourdough microflora. Interactions between lactic acid bacteria and yeasts: metabolism of carbohydrates. Applied Microbiology and Biotechnology 41: 456460. https://doi.org/10.1007/BF00939035.

Gobbetti, M., De Angelis, M., Corsetti, A., Di Cagno, R. (2005). Biochemistry and physiology of sourdough lactic acid bacteria. Trends in Food Science and Technology 16(1-3): 57-69. https:// doi.org/10.1016/j.tifs.2004.02.013.

Goldman, D. (2020). Initial observations of psychological and behavioral effects of COVID-19 in the United States, using Google Trends data. SocArXiv jecqp, Center for Open Science. Pp. 1-6. https:// doi.org/10.31219/osf.io/jecqp.

Hammes, W.P., Gänzle, M.G. (1998). Sourdough breads and related products. In: Wood, B.J.B. (ed.) Microbiology of Fermented Foods. Springer, Boston, MA, USA. Pp. 199-216-. https://doi.org/ 10.1007/978-1-4613-0309-1_8.

Hansen, Å., Hansen, B. (1996). Flavour of sourdough wheat bread crumb. European Food Research and Technology 202: 244-249. https://doi.org/10.1007/BF01263548.

Hansen, A., Schieberle, P. (2005.) Generation of aroma compounds during sourdough fermentation: applied and fundamental aspects.
Trends in Food Science and Technology 16(1-3): 85-94. https:// doi.org/10.1016/j.tifs.2004.03.007

Harris, L. (2003). Sourdough culture. Gastronomica 3(3): 76-79. https:// doi.org/10.1525/gfc.2003.3.3.76

Hiremath, P., Suhas Kowshik, C.S., Manjunath, M., Shettar, M. (2020). COVID 19: impact of lock-down on mental health and tips to overcome. Asian Journal of Psychiatry 51: 102088. https://doi.org/10. 1016/j.ajp.2020.102088.

Katina, K., Arendt, E., Liukkonen, K.H., Autio, K., Flander, L., Poutanen, K. (2005). Potential of sourdough for healthier cereal products. Trends in Food Science and Technology 16 (1-3): 104112. https://doi.org/10.1016/j.tifs.2004.03.008.

Lambert, K.G., Nelson, R.J., Jovanovic, T., Cerdá, M. (2015). Brains in the city: neurobiological effects of urbanization. Neuroscience and Biobehavioral Reviews 58: 107-122. https://doi.org/10.1016/j. neubiorev.2015.04.007.

Lebedenko, T., Kozhevnikova, V., Novichkova, T., Kotuzaki, O. (2019). Features of determining the quality of ethnic sourdoughs and ways of using them in baking and catering business. EUREKA: Life Sciences 4(4): 36-44. https://doi.org/10.21303/2504-5695.2019. 00971

Lidz, F. (2020). At the sourdough library, with some very old mothers. The New York Times. Accessed November 21, 2020. https://www. nytimes.com/2020/04/11/science/sourdough-bread-starter-library. html.

Logan, B.K., Distefano, S. (1998). Ethanol content of various foods and soft drinks and their potential for interference with a breath-alcohol test. Journal of Analytical Toxicology 22(3): 181-183. https://doi. org/10.1093/jat/22.3.181.

Papadimitriou, K., Zoumpopoulou, G., Georgalaki, M., Alexandraki, V., Kazou, M., Anastasiou, R., Tsakalidou, E. (2019). Chapter 6 Sourdough Bread. In: Galanakis, C.M. (ed.) Innovations in Traditional Foods. Elsevier-Woodhead Publishing, Cambridge, UK. Pp. 127-158. https://doi.org/10.1016/B978-0-12-814887-7. 00006-X.

Poutanen, K., Flander, L., Katina, K. (2009). Sourdough and cereal fermentation in a nutritional perspective. Food Microbiology 26(7): 693-99. https://doi.org/10.1016/j.fm.2009.07.011.

Rosell, C.M. (2019). Trends in science of doughs and bread quality. In: Preedy, V.R., Ross Watson, R (eds.) Flour and Breads and their Fortification in Health and Disease Prevention (Second Edition). Academic Press, Cambridge, MA USA. Pp. 333-343. https://doi. org/10.1016/b978-0-12-814639-2.00026-5.

Rossi, R., Socci, V., Talevi, D., Mensi, S., Niolu, C., Di Marco, A., Rossi, A., Siracusano, A., Di Lorenzo, G. (2020). COVID-19 pandemic and lockdown measures impact on mental health among the general population in Italy. Frontiers in Psychiatry 11: 790. https://doi.org/ 10.3389/fpsyt.2020.00790.

Sponagle, J. (2020). Sourdough baking sees rise in popularity during COVID-19 pandemic. CBC News. Accessed December 22, 2020. https://www.cbc.ca/news/canada/north/sourdough-popular-covid$19-1.5529649$

Publisher's Note Springer Nature remains neutral with regard to jurisdictional claims in published maps and institutional affiliations. 